OPEN ACCESS

Edited by:

Xiazi Xiao,

Central South University, China

Reviewed by:

Shuoxue Jin,

Institute of High Energy Physics (CAS),

China

Dongping Liu,

Dalian University of Technology, China

Huiqiu Deng,

Hunan University, China

*Correspondence:

Chenxu Wang

cxwang@pku.edu.cn

Specialty section: This article was submitted to Mechanics of Materials, a section of the journa

Frontiers in Materials

Received: 05 January 2022 Accepted: 24 January 2022 Published: 23 February 2022

Citation:

Huang J, Liu H, Gao Z, Su Y, Liu Q, Ge W, Luo F, Xia S, Cao L, Xue J, Wang $Y$ and Wang $C$ (2022) Helium-

Hydrogen Synergistic Effects in

Structural Materials Under Fusion

Neutron Irradiation.

Front. Mater. 9:849115

doi: 10.3389/fmats.2022.849115

\section{Helium-Hydrogen Synergistic Effects in Structural Materials Under Fusion Neutron Irradiation}

\author{
Jia Huang ${ }^{1}$, Haocheng Liu ${ }^{2}$, Zhiying Gao ${ }^{1}$, Yue Su ${ }^{1}$, Qingyuan Liu ${ }^{1}$, Wei Ge ${ }^{1}$, Fengping Luo ${ }^{1}$, \\ Songqin Xia ${ }^{3}$, Liuxuan $\mathrm{CaO}^{4}$, Jianming Xue ${ }^{1}$, Yugang Wang ${ }^{1}$ and Chenxu Wang ${ }^{1 *}$ \\ ${ }^{1}$ State Key Laboratory of Nuclear Physics and Technology, Center for Applied Physics and Technology, Peking University, Beijing, \\ China, ${ }^{2}$ State Power Investment Corporation Research Institute, Beijing, China, ${ }^{3}$ School of Nuclear Science and Engineering, \\ North China Eletric Power University, Beijing, China, ${ }^{4}$ College of Energy, Xiamen University, Xiamen, China
}

In fusion reactors, $14 \mathrm{MeV}$ high-energy neutron irradiation of structural materials will produce large amounts of helium and hydrogen simultaneously with displacement defects. These $\mathrm{He}$ and $\mathrm{H}$ atoms will interact with displacement defects, leading to He$\mathrm{H}$ synergistic effects and aggravating the irradiation damage. Currently, there exist no available high-flux fusion neutron sources. Additionally, the neutron energy spectrum and the generation of $\mathrm{He}$ and $\mathrm{H}$ in fission reactors or spallation neutron sources greatly differ from those in fusion reactors. Multi-ion beam irradiation is a promising method to emulate the synergistic effects induced by fusion neutron irradiation. This review summarizes the experimental studies on the $\mathrm{He}-\mathrm{H}$ synergistic effects, and analyzes the effects of $\mathrm{He}$ and $\mathrm{H}$ on cavity evolution and swelling under multi-ion beam irradiation. The roles of various experimental factors are also discussed. More systematically controlled experiments are suggested to develop a comprehensive understanding of $\mathrm{He}-\mathrm{H}$ synergistic effects in structural materials.

Keywords: advanced nuclear energy system, fusion neutron irradiation, transmutation reaction, helium-hydrogen synergistic effects, cavity evolution, swelling

\section{INTRODUCTION}

The development of safe, efficient, and clean advanced nuclear energy systems is a frontier topic and important support for sustainable development all over the world. As the most promising candidate, fusion energy has the potential to solve the global energy crisis. At present, the most mature and popular scheme of fusion energy is the magnetic confinement fusion energy that still faces several key challenges, such as the tolerance of structural materials in extreme environments (Zinkle and Snead, 2014; Knaster et al., 2016).

In nuclear energy systems, the performance of structural materials not only determines the capacity efficiency, output power, and service life, but also contributes to the safety of systems. In advanced nuclear energy systems such as fusion reactors, structural materials are exposed to harsh and complex service environments such as strong neutron radiation and high temperatures for long periods. High-flux neutron irradiation would cause a large number of displacement defects and the dose could be up to hundreds of dpa (displacement per atom), resulting in serious damage and properties degradation to structural materials (Zinkle and Busby, 2009). Therefore, it is generally believed that the property degradation and failure of key structural materials in long-term operation is one of the most pressing and challenging issues in the research of advanced nuclear energy systems (Was et al., 2019). 
The irradiation damage significantly depends on the neutron energy spectrum, nuclear reactions, temperature, irradiation dose, and dose rate. In fusion reactors, the deuterium-tritium reaction will produce $14 \mathrm{MeV}$ high-energy neutrons that cause not only massive displacement defects but also plenty of helium and hydrogen gas atoms through $(n, a)$ and $(n, p)$ transmutation reactions with elements such as iron in blanket structural materials. For iron-based materials, the irradiation dose would be 20-30 dpa per year. The production rate (gas-dose ratio) of helium and hydrogen would be up to $10-15 \mathrm{appm} / \mathrm{dpa}$ and 40-50 appm/dpa, which are more than 10 and 40 times greater than those in fission reactors, respectively (Dai et al., 2020).

It has been recognized that the accumulation of helium in structural materials would prompt cavity nucleation and usually enhance the swelling (Trinkaus and Singh, 2003; Molvik et al., 2010). The term cavity refers to a small volume composed of vacancies and/or helium and/or hydrogen gas atoms, thus is used here as a generic term for voids and bubbles (Zinkle, 2020). Hydrogen might escape rapidly from metals due to its low solubility and high mobility, which is dependent on temperature. It has been demonstrated that hydrogen has positive binding energy with irradiation defects and would be effectively trapped inside the materials at a certain temperature (Abramov and Eliezer, 1988; Binyukova et al., 2007). The current studies have shown that displacement damage will interact with simultaneously produced helium and/or hydrogen, resulting in synergistic effects in blanket structural materials. The $\mathrm{He}-\mathrm{H}$ synergistic effects would greatly influence the evolution of cavities and other damaged microstructures, further aggravating the performance degradation of structural materials, such as swelling and radiation hardening. The threats to the operation of structural materials caused by synergistic damage may far exceed those caused by displacement defects alone. (Marian et al., 2015).

However, there exist no available high-flux fusion neutron sources or integrated materials testing facilities. Some planned fusion neutron sources around the world, such as IFMIF-DONES (Donné, 2019) and A-FNS (Muroga et al., 2020), will take 10 years to be built. Currently, there are only very limited lowdose fusion neutron irradiation data from RTNS-II (Rotation Target Neutron Source II) in the 1980s (Kiritani et al., 1984). Experimental studies are limited, and computational simulations have not yet provided an accurate description of the synergistic interaction process. And there are many challenges facing multiscale simulations of synergistic effects, such as the lack of ternary potential function and effective simulation methods for the evolution of defect clusters at a long-time scale. Therefore, the study of $\mathrm{He}-\mathrm{H}$ synergistic effects is extremely challenging.

\section{RADIATION EFFECTS IN MATERIALS UNDER FUSION, FISSION, AND SPALLATION NEUTRON IRRADIATION}

The radiation resistance of nuclear materials is usually evaluated using reactor irradiation (Was et al., 2014). In the absence of an available fusion neutron source, researchers have previously carried out neutron irradiation experiments on fusion reactor structural materials using fission reactors and spallation neutron sources (Stork et al., 2017).

However, due to the intrinsic difference in the neutron energy spectrum, the results obtained from fusion neutron irradiation are significantly different from those of fission and spallation neutron irradiation. Unlike fusion neutron, the fission neutron irradiation primarily produces displacement defects with only small amount of transmuted hydrogen and helium. The available low-dose fusion neutron irradiation results mainly focused on the structure and evolution of defect clusters in pure metals and simple alloys (Kiritani et al., 1984; Shimomura et al., 1985; Shimomura et al., 1988; Singh and Zinkle, 1993). Muroga et al. (1992) reported that the type and size of defect clusters in copper under fission and fusion neutron irradiation were similar, yet the density showed a pronounced difference. And this difference corresponded well to the comparison of yield strength changes under the two types of irradiation, which showed that the needed dose for fission neutron is 17 times greater than that for fusion neutron to produce the same yield strength change and hardening in annealed copper (Heinisch, 1988).

The differences in iron were also significant. Matsui et al. (1985) investigated the temperature dependence of yield strength of iron irradiated by RTNS-II and KUR (Kyoto University Reactor, fission neutron). It was shown that the temperature dependence in both cases was similar and only slightly changed at low temperatures. In the high-temperature range, the yield strength of iron under RTNS-II irradiation decreased more rapidly with increasing temperature than that under KUR irradiation, and the two dependence curves crossed, suggesting detectable differences in defect structures between the two types of irradiations. Matsui et al. (1988) also compared the resistivity of iron after fission- and fusion-neutron irradiation and found that the induced resistivity of iron under fusion neutron irradiation was 2 times larger than that under fission neutron irradiation. Meanwhile, Okada et al. (1991) reported the variance of mechanical property changes of iron under fusion and fission neutron irradiation. And they pointed out that there were much more invisible defect clusters for fusion neutron irradiation by comparing the testing results with the model predictions.

In addition to mechanical properties, researchers also found that the irradiation-induced swelling behaviors in metals were quite different under the two kinds of neutron irradiation. It could accumulate required $\mathrm{He}$ concentration for cavity stabilization at relatively low doses under fusion neutron irradiation, with a production rate of about $10 \mathrm{appm} / \mathrm{dpa}$. In the 1980s, Muroga et al. (1988) compared the microstructures and cavity swelling in annealed pure nickel irradiated by JOYO (Japanese Experimental Fast Reactor, fission neutron) and RTNSII, with irradiation temperature of $673-773$ and $723 \mathrm{~K}$, respectively. The doses in these two cases were $0.067-4.3 \mathrm{dpa}$ and $0.00057-0.020 \mathrm{dpa}$, and the dose rates were $1.8-21.6 \times$ $10^{-8} \mathrm{dpa} / \mathrm{s}$ and $0.0084-0.30 \times 10^{-8} \mathrm{dpa} / \mathrm{s}$, respectively. They found that the swelling after fusion neutron irradiation was considerably higher than that after fission neutron irradiation, 


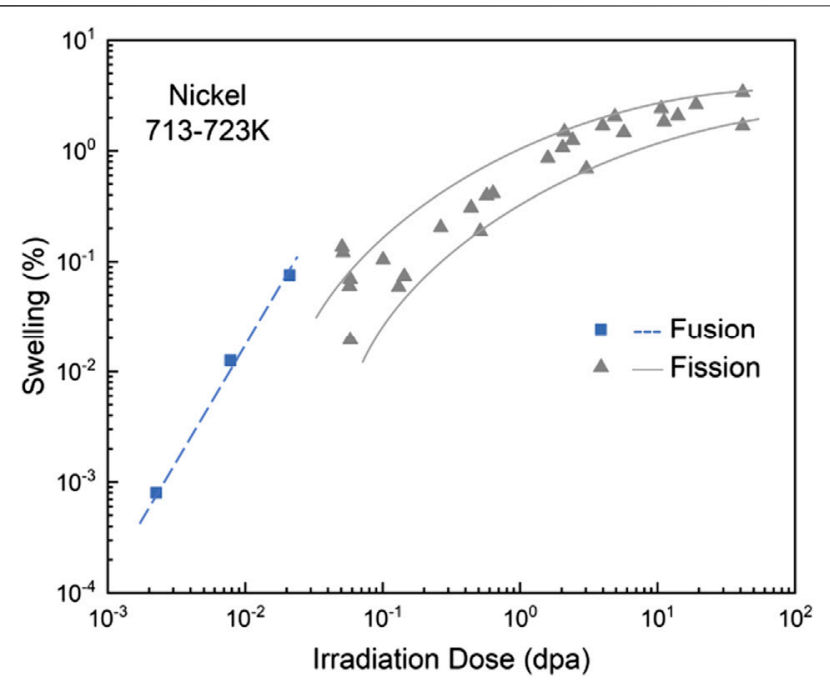

FIGURE 1 | Variation of cavity swelling with dose in nickel irradiated with fission and fusion neutrons. The swelling after low-dose fusion neutron irradiation is much greater than that after fission neutron irradiation. Reproduced with permission from Singh and Zinkle (1993). Copyright 1993 Elsevier.

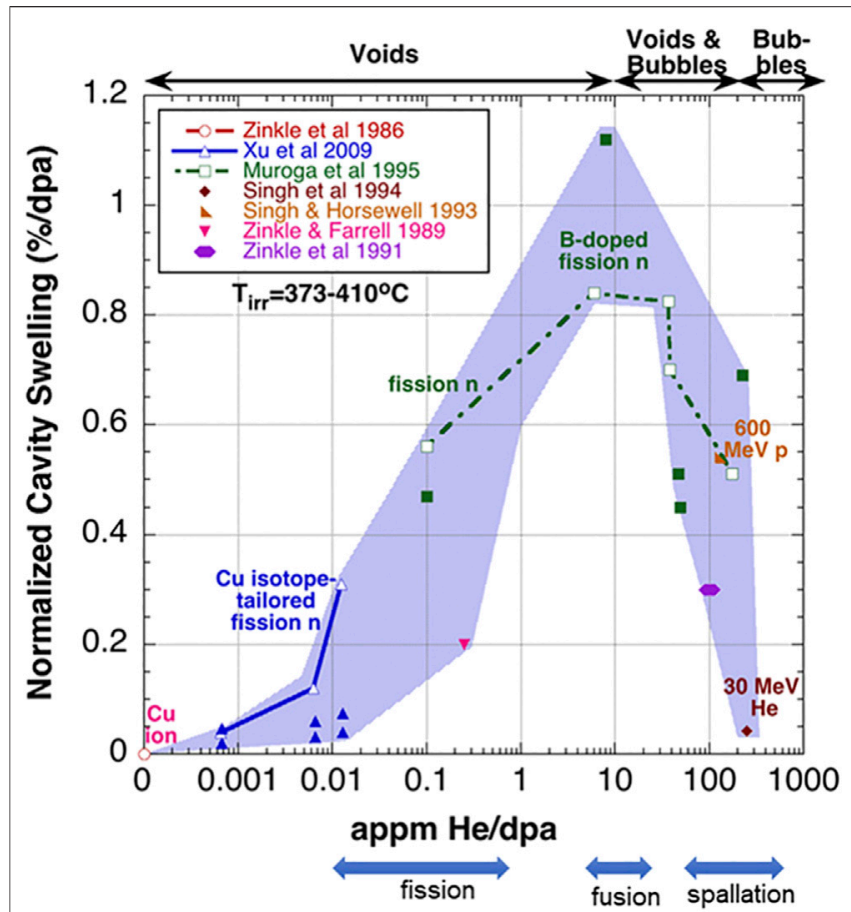

FIGURE 2 | The dependence of cavity swelling in pure $\mathrm{Cu}$ on the production rate of $\mathrm{He}$. The dependence is nonmonotonic and a peak swelling occurs at about 10 appm He/dpa. (Bhattacharya and Zinkle, 2020).

regardless of the similarity in the density of cavity. Considering the possible role of different damage rates, the increase in swelling was still significant, revealing pronounced $\mathrm{He}-\mathrm{H}$ synergistic effects. As shown in Figure 1, Singh and Zinkle (1993)

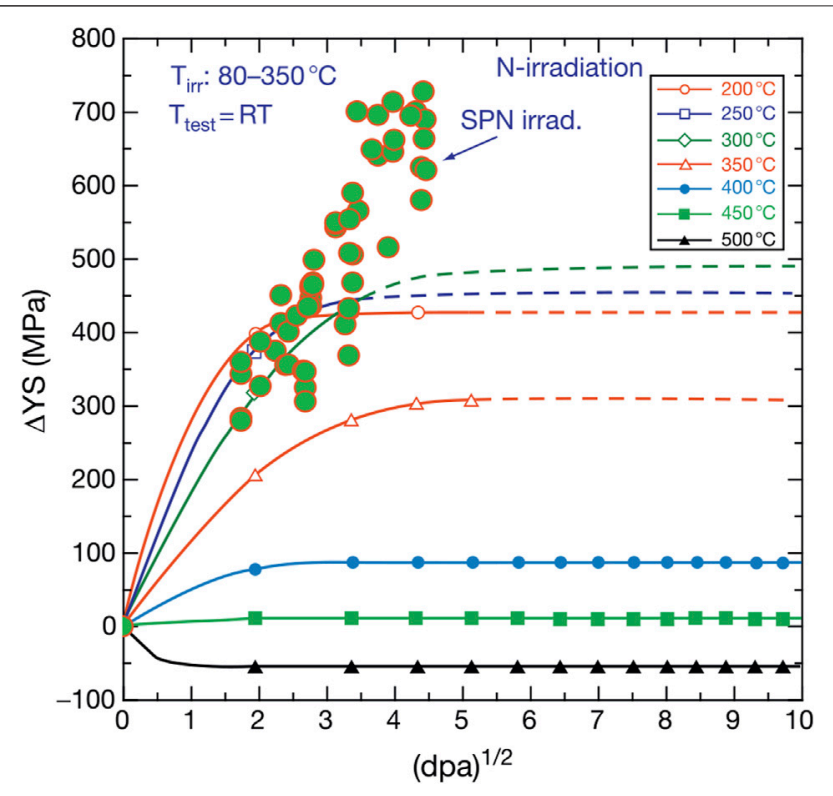

FIGURE 3 | Variation of irradiation hardening with dose induced by spallation and fission neutron irradiation. As dose increases, the hardening induced by fission neutron irradiation saturates, while that induced by spallation neutron irradiation do not saturate and reaches remarkable levels. (Dai et al., 2020).

compared Muroga's data with other fission neutron irradiation data and further consolidated the significant enhancement of swelling, which was also found in copper under low-dose fusion neutron irradiation (Kiritani et al., 1990).

It has been widely confirmed that the irradiation swelling significantly depends on the He-dose ratio (appm/dpa), and the dependence is non-monotonic (Bhattacharya and Zinkle, 2020), as shown in Figure 2. Researchers have tried to achieve fusionrelevant $\mathrm{He}$ production rate, i.e., $\mathrm{He} / \mathrm{dpa}$ ratio, by applying a $\mathrm{Ni}$ bearing implanter foil on the surface of the irradiated materials for high-energy a particles under fission neutron irradiation, or doping $\mathrm{Ni}$ or $\mathrm{B}$ isotopes in materials (Hashimoto et al., 2002; Tanigawa et al., 2011). However, the helium profile produced in the foil differs from the distribution of neutron-induced damages, and the doping elements will affect the composition and properties as well as responses of materials to irradiation (Stork et al., 2017; Dai et al., 2020).

Meanwhile, the concentration of simultaneously produced hydrogen and helium under spallation neutron irradiation is one order of magnitude higher than those under fusion neutron irradiation. Actually, in addition to high-energy neutron irradiation, the materials would be irradiated by high energy and current proton beams simultaneously in spallation neutron source (Oliver et al., 2006). For example, in the SINQ (Swiss Spallation Neutron Source), the typical damage levels could reach up to about $20 \mathrm{dpa}$ and 1,800 appm He (Jia and Dai, 2006). Microstructural damage and mechanical properties changes in AUSS (Austenitic stainless steels) and FMS (Ferritic-martensitic steels) under spallation neutron irradiation have been widely investigated. As shown in 
Figure 3, the materials' hardening induced by spallation neutron irradiation appears to be similar to that under fission neutron irradiation at low doses. As dose increases, the hardening induced by fission neutron irradiation gradually saturates, while that by spallation neutron irradiation increases continuously. This may be primarily attributed to the effects of $\mathrm{He}$ and $\mathrm{H}$. Thus, given the great difference in energy spectrum and transmutation production of $\mathrm{He}$ and $\mathrm{H}$, the damage effects induced by spallation neutron irradiation might be different from those by fusion neutron irradiation.

In summary, fission and spallation neutron irradiation cannot accurately emulate the synergistic effects of displacement defects, helium, and hydrogen during fusion neutron irradiation. Therefore, fusion neutron source or other emulation methods that can produce comparable $\mathrm{He}$ and $\mathrm{H}$ concentration to fusion reactors is necessary to help investigate the $\mathrm{He}-\mathrm{H}$ synergistic effects in structural materials.

\section{MULTI-ION BEAM IRRADIATION}

Multi-ion beam irradiation, i.e., $\mathrm{HI}$ (Heavy Ion) $+\mathrm{He}+\mathrm{H}$, has been considered as the promising surrogate for fusion neutron irradiation. By coupling two or three accelerators, multi-ion beam irradiation can simultaneously produce displacement damage in the materials, as well as appropriate He/dpa ratio and $\mathrm{H} / \mathrm{dpa}$ ratio equivalent to those in fusion reactors. Therefore, it can help to study the $\mathrm{He}-\mathrm{H}$ synergistic effects induced by fusion neutron irradiation. Unlike neutron irradiation, multi-ion beam irradiation could achieve high dose, high $\mathrm{He}$ and $\mathrm{H}$ levels in a very short period of time with little residual radioactivity. Moreover, the irradiation parameters (ion species and energy, temperature, dose, dose rate, $\mathrm{He} / \mathrm{H}$ production rate) can be widely varied and wellcontrolled. Nevertheless, there are some unavoidable disadvantages of multi-ion beam irradiation. The shallow penetration depth would result in defect-depleted zone near free surfaces and limit post-irradiation characterization of bulk mechanical properties. In addition, the doping of additional interstitial atoms and ultra-high damage rate might produce artifacts that mislead the analysis of damaged microstructures and radiation effects. (Was, 2015; Zinkle and Snead, 2018).

Here, we review the experimental studies of the $\mathrm{He}-\mathrm{H}$ synergistic effects in blanket structural materials of fusion reactors. The possible mechanisms of helium and hydrogen in swelling and cavities evolution under multi-ion beam irradiation are analyzed. We also discussed the role of various experimental factors, such as irradiation temperature, gas-dose ratio of $\mathrm{He}$ and $\mathrm{H}$ in the radiation effects. These findings could help understand the application and limitations of multi-ion beam irradiation methods in studying $\mathrm{He}-\mathrm{H}$ synergistic effects. More systematic controlled experiments are suggested to investigate the role of damage rate, develop a comprehensive understanding of $\mathrm{He}-\mathrm{H}$ synergistic effects, and determine the potential synergistic damage of structural materials.

\section{HE-H SYNERGISTIC EFFECTS ON CAVITY EVOLUTION AND SWELLING}

Table 1 summarizes the typical experimental results using multiion beam irradiation. There seems to be a certain effect of promoting the cavity nucleation when both $\mathrm{He}$ and $\mathrm{H}$ are present. However, due to the lack of understanding of the original interaction progress and evolution mechanism, the synergistic effects on cavity size and swelling are controversial.

$\mathrm{He}$ and $\mathrm{H}$ present in materials are more likely to interact with vacancies than interstitial atoms. Helium and hydrogen atoms can bound to vacancies to form $\mathrm{He}-\mathrm{V}, \mathrm{H}-\mathrm{V}$, and $\mathrm{He}-\mathrm{H}-\mathrm{V}$ pairs and clusters, which could be the embryos of cavities (Jung et al., 2001; Trinkaus and Singh, 2003; Henriksson et al., 2005) and influence vacancy migration energy $\left(E_{m}^{v}\right)$ (Liu et al., 2019). Liu et al. calculated the $E_{m}^{v}$ by measuring the growth rates of irradiation-induced dislocation loops under sequential $\mathrm{He} / \mathrm{H}$ and electron irradiation at different temperatures. The results suggested that $E_{m}^{v}$ under different irradiation conditions followed the order that pre-implantation $(\mathrm{He}+\mathrm{H})>\mathrm{He}>\mathrm{H}$. The authors explained that He preferred occupying substitutional position sites and formed $\mathrm{He}-\mathrm{V}$ clusters with vacancies easily, causing the increase of $E_{m}^{v}$. H-V clusters could be also formed, yet they were usually weaker than $\mathrm{He}-\mathrm{V}$. Moreover, $\mathrm{H}$ could strengthen the binding of $\mathrm{He}$ and $\mathrm{V}$, and then formed $\mathrm{He}-\mathrm{H}-\mathrm{V}$ clusters that further hinder the movement of vacancies. These results suggested that the presence of $\mathrm{He}$ and $\mathrm{H}$ would contribute to the aggregation of vacancies and the formation of cavities, further influencing the irradiation-induced swelling.

The increase of swelling caused by $\mathrm{He}-\mathrm{H}$ synergistic effects in materials under different experimental conditions had been demonstrated in previous studies (Farrell and Lee, 1985; Farrell and Lee, 1987; Sekimura et al., 2000; Tanaka et al., 2004; Borodin et al., 2013; Brimbal et al., 2015; Kupriiyanova et al., 2016; Liu et al., 2021). However, some results (Farrell et al., 1978; Hamada et al., 1997; Kupriiyanova et al., 2016; Jiang et al., 2020) showed that He-H synergistic effects on swelling are not monotonic, indicating that the swelling may not always be enhanced but also be suppressed under triple beam irradiation. For example, Jiang et al. (2020) recently reported that the cavity swelling of alpha-Cr was $0.8 \%$ under single beam irradiation, while a lower swelling of $0.5 \%$ was observed under triple beam irradiation.

Cavity swelling is usually evaluated by the volume ratio of cavities and the matrix (Jiang et al., 2020). The size and number density of cavities strongly influences swelling. Thus, to better understand the mechanism of swelling, we need to discuss the synergistic effects on specific cavity properties such as average size and number density separately. Almost all the results in Table 1 show that the number density of the cavity increased as $\mathrm{He}$ and $\mathrm{H}$ were introduced simultaneously, suggesting that the $\mathrm{He}-\mathrm{H}$ synergistic effects would prompt the nucleation and dispersion of the cavity. The only exception that the density decreased in Sekimura et al. (2000) might be attributed to the differences in materials and the gas-dose ratio of $\mathrm{He}$ and $\mathrm{H}$.

The change of cavity size in the synergistic effects is somewhat complicated. In most studies shown in Table $\mathbf{1}$, the $\mathrm{He}-\mathrm{H}$ 
TABLE 1 | The summary of typical studies on the He-H synergistic effects under multi-ion beam irradiation.

\begin{tabular}{|c|c|c|c|c|c|c|c|c|c|c|c|c|c|}
\hline \multirow[t]{2}{*}{ Materials } & \multirow{2}{*}{$\begin{array}{l}\text { Irradiation } \\
\text { beam }\end{array}$} & \multirow{2}{*}{$\begin{array}{l}\text { Temp./Dose (Dose } \\
\text { Rate)/Gas conc. }\end{array}$} & \multicolumn{3}{|c|}{ The effect of $\mathrm{He}+\mathrm{H}^{\mathrm{a}}$} & \multicolumn{3}{|c|}{ The effect of $\mathrm{H}^{\mathrm{a}}$} & \multicolumn{3}{|c|}{ The effect of $\mathrm{He}^{\mathrm{a}}$} & \multirow[t]{2}{*}{ Annotation } & \multirow[t]{2}{*}{ References } \\
\hline & & & Swelling & Density & Sizê & Swelling & Density & Size & Swelling & Density & Size & & \\
\hline $\begin{array}{l}\text { Fe-17Cr-17Ni- } \\
2.5 \mathrm{Mo} \text { AUSS }\end{array}$ & $\begin{array}{l}4 \mathrm{MeV} \mathrm{Ni} \\
.2-.4 \mathrm{MeV} \mathrm{He} \\
.2-.4 \mathrm{MeV} \mathrm{D}\end{array}$ & $\begin{array}{l}898 \mathrm{~K}, 70 \mathrm{dpa}, 7.8 \times 10^{-3} \\
\mathrm{dpa} / \mathrm{s}, 20 \mathrm{appm} \mathrm{He} / \mathrm{dpa} \\
50 \mathrm{appm} \mathrm{D/dpa}\end{array}$ & $\downarrow$ & $\uparrow$ & $\downarrow$ & $\uparrow$ & $\uparrow$ & $\downarrow$ & $\downarrow$ & $\uparrow$ & $\downarrow$ & & Farrell et al. (1978) \\
\hline Fe-Cr Alloy & $\begin{array}{l}4 \mathrm{MeV} \mathrm{Fe} \\
.2-.4 \mathrm{MeV} \mathrm{He} \\
.2-.4 \mathrm{MeV} \mathrm{D}\end{array}$ & $\begin{array}{l}725-950 \text { K, } 10 \text { dpa } \\
10 \text { appm He/dpa } \\
41 \text { appm D/dpa }\end{array}$ & & & & & & & & & & $\begin{array}{l}\text { As temp. increases, swelling \& size } \\
\text { increase first and then decrease }\end{array}$ & Horton et al. (1981) \\
\hline $\begin{array}{l}\text { Fe-9Cr-1Mo } \\
\text { Steel }\end{array}$ & $\begin{array}{l}.2-.4 \mathrm{MeV} \mathrm{He} \\
.2-.4 \mathrm{MeV} \mathrm{D}\end{array}$ & $\begin{array}{l}10 \text { appm He/dpa, } \\
45 \text { appm D/dpa }\end{array}$ & $\uparrow$ & $\uparrow$ & $\downarrow$ & $\downarrow$ & $\downarrow$ & $\uparrow$ & $\uparrow$ & $\uparrow$ & $\downarrow$ & $\begin{array}{l}\text { As temp. increases, swelling \& size } \\
\text { increase for triple beam. Bimodal } \\
\text { cavities exist for dual \& triple beam at } \\
\text { low temp }\end{array}$ & $\begin{array}{l}\text { Farrell and Lee } \\
\text { (1985) }\end{array}$ \\
\hline $\begin{array}{l}\text { Fe-10Cr-6Mo- } \\
0.5 \mathrm{Nb} \text { Steel }\end{array}$ & $\begin{array}{l}\text { 2-.4 MeV He } \\
.2-.4 \mathrm{MeV} \mathrm{D}\end{array}$ & $\begin{array}{l}673-873 \mathrm{~K}, \\
100-120 \mathrm{dpa}, 6 \times 10^{-3} \\
\mathrm{dpa} / \mathrm{s}, \\
10 \mathrm{appm} \mathrm{He} / \mathrm{dpa}, \\
45 \mathrm{appm} \mathrm{D/dpa}\end{array}$ & $\uparrow$ & $\uparrow$ & $\downarrow$ & $\downarrow$ & $\downarrow$ & $\uparrow$ & $\uparrow$ & $\uparrow$ & $\downarrow$ & $\begin{array}{l}\text { As temp. increases, swelling \& size } \\
\text { increase for triple beam. Bimodal } \\
\text { cavities exist for dual \& triple beam at } \\
\text { low temp }\end{array}$ & $\begin{array}{l}\text { Farrell and Lee } \\
\text { (1987) }\end{array}$ \\
\hline Pure V & $\begin{array}{l}1 \mathrm{MeV} \mathrm{He} \\
950 \mathrm{keV} \mathrm{H}\end{array}$ & $\begin{array}{l}773-973 \mathrm{~K}, 1 / 5 / 15 / 50 \\
\mathrm{dpa}, 3 \times 10^{-3 /} \mathrm{dpa} / \mathrm{s} \\
\text { 15/30/60 appm He/dpa, } \\
30 \mathrm{appm} \mathrm{D/dpa}\end{array}$ & & & & $\downarrow^{1}$ & $\uparrow$ & $\downarrow$ & $\downarrow$ & $\uparrow$ & $\downarrow$ & $\begin{array}{l}\text { 1: The effect of } \mathrm{H} \text { refers to }(H \mathrm{H}+\mathrm{H}) \\
\text { vs. }(\mathrm{HI}) \text {. Bimodal cavities exist and } \\
\text { depend on temp }\end{array}$ & Kano et al. (1993) \\
\hline $\begin{array}{l}\text { Fe-14Cr-16Ni- } \\
2.5 \mathrm{Mo} \text { AUSS }\end{array}$ & $\begin{array}{l}1 \mathrm{MeV} \mathrm{He} \\
350 \mathrm{keV} \mathrm{H}\end{array}$ & $\begin{array}{l}573-673 \mathrm{~K}, \\
56 \mathrm{dpa}, \\
200 \mathrm{appm} \mathrm{He/dpa} \\
370 \mathrm{appm} \mathrm{H/dpa}\end{array}$ & $\downarrow^{1}$ & $\uparrow$ & $\downarrow$ & & & & & & & $\begin{array}{l}\text { 1: The effect of } \mathrm{He}+\mathrm{H} \text { refers to (triple } \\
\text { beam with high-conc. He and } \mathrm{H} \text { ) vs. } \\
\text { (dual } \mathrm{HI}+\mathrm{He} \text {, with low-conc. } \mathrm{He} \text { ) }\end{array}$ & $\begin{array}{l}\text { Hamada et al. } \\
\text { (1997) }\end{array}$ \\
\hline Pure V & $\begin{array}{l}12 \mathrm{MeV} \mathrm{Ni} \\
1 \mathrm{MeV} \mathrm{He} \\
350 \mathrm{keV} \mathrm{H}\end{array}$ & $\begin{array}{l}873 \mathrm{~K}, 30 \mathrm{dpa}, 4 \times 10^{-4} \\
\text { dpa/s 10/20 appm He/dpa } \\
\text { 10/20 appm H/dpa }\end{array}$ & $\uparrow$ & $\downarrow$ & $\uparrow$ & $\begin{array}{l}\rightarrow^{1} \\
\uparrow\end{array}$ & $\rightarrow$ & $\begin{array}{l}\rightarrow \\
\uparrow\end{array}$ & $\uparrow$ & $\uparrow$ & $\rightarrow$ & $\begin{array}{l}\text { 1: The effect of } \mathrm{H} \text { refers to }(H \mathrm{H}+\mathrm{H}) \\
\text { vs. }(H I)\end{array}$ & $\begin{array}{l}\text { Sekimura et al. } \\
(2000)\end{array}$ \\
\hline $\mathrm{F} 82 \mathrm{H}$ & $\begin{array}{l}1.05 \mathrm{MeV} \mathrm{He} \\
380 \mathrm{keV} \mathrm{H}\end{array}$ & $\begin{array}{l}743-873 \mathrm{~K}, 50 \mathrm{dpa}, 1.6 \times \\
10^{-3} \mathrm{dpa} / \mathrm{s}, \\
\text { Fusion: } 18 \mathrm{appm} \mathrm{He} / \mathrm{dpa} \text {, } \\
70 \mathrm{dppm} \mathrm{H} / \mathrm{dpa} \text {, } \\
\text { Spallation: } 180 \mathrm{appm} \mathrm{He} / \\
\text { dpa, } 1700 \mathrm{appm} \mathrm{H/dpa}\end{array}$ & $\uparrow^{1}$ & $\uparrow$ & $\uparrow$ & $\uparrow^{2}$ & $\rightarrow$ & $\uparrow$ & & & & $\begin{array}{l}\text { 1: The effect of } \mathrm{He}+\mathrm{H} \text { refers to } \\
\text { (spallation triple beam) vs. (fusion } \\
\text { dual beam) } \\
\text { 2: The effect of } \mathrm{H} \text { obtained for the } \\
\text { fusion condition } \\
\text { As temp. increases, the swelling \& } \\
\text { size decrease for fusion condition }\end{array}$ & $\begin{array}{l}\text { Wakai et al. (2002), } \\
\text { Wakai et al. (2003) }\end{array}$ \\
\hline
\end{tabular}


TABLE 1 | (Continued) The summary of typical studies on the He-H synergistic effects under multi-ion beam irradiation.

\begin{tabular}{|c|c|c|c|c|c|c|c|c|c|c|c|c|c|}
\hline \multirow[t]{2}{*}{ Materials } & \multirow{2}{*}{$\begin{array}{l}\text { Irradiation } \\
\text { beam }\end{array}$} & \multirow{2}{*}{$\begin{array}{l}\text { Temp./Dose (Dose } \\
\text { Rate)/Gas conc. }\end{array}$} & \multicolumn{3}{|c|}{ The effect of $\mathrm{He}+\mathrm{H}^{\mathrm{a}}$} & \multicolumn{3}{|c|}{ The effect of $\mathbf{H}^{\mathrm{a}}$} & \multicolumn{3}{|c|}{ The effect of $\mathrm{He}^{\mathrm{a}}$} & \multirow[t]{2}{*}{ Annotation } & \multirow[t]{2}{*}{ References } \\
\hline & & & Swelling & Density & $\overline{\text { Size }}$ & Swelling & Density & $\overline{\text { Size }}$ & Swelling & Density & $\overline{\text { Size }}$ & & \\
\hline \multirow[t]{2}{*}{ Fe-12Cr Alloy } & $10.5 \mathrm{MeV} \mathrm{Fe}$ & $\begin{array}{l}743-873 \mathrm{~K}, 50 \mathrm{dpa}, 1.6 \times \\
10^{-3} \mathrm{dpa} / \mathrm{s}\end{array}$ & $\uparrow$ & $\uparrow$ & & $\rightarrow^{1}$ & $\rightarrow$ & $\rightarrow$ & $\downarrow$ & $\uparrow$ & $\downarrow$ & $\begin{array}{l}\text { 1: The effect of } \mathrm{H} \text { refers to }(H \mathrm{H}+\mathrm{H}) \\
\text { vs. }(\mathrm{HI}) \text {. As temp. increases, the } \\
\text { swelling \& size increase first and } \\
\text { then decrease }\end{array}$ & $\begin{array}{l}\text { Tanaka et al. } \\
\text { (2004) }\end{array}$ \\
\hline & $\begin{array}{l}1.05 \mathrm{MeV} \mathrm{He} \\
380 \mathrm{keV} \mathrm{H}\end{array}$ & $\begin{array}{l}10 \mathrm{appm} \mathrm{He} / \mathrm{dpa} \\
40 \mathrm{dppm} \mathrm{H/dpa}\end{array}$ & & & & $\uparrow$ & $\downarrow$ & $\uparrow$ & & & & & \\
\hline \multirow[t]{2}{*}{ 18Cr10NitiSS } & $1.8 \mathrm{MeV} \mathrm{Cr}$ & $\begin{array}{l}723-923 \mathrm{~K}, 50 \mathrm{dpa}, 1 \times \\
10^{-2} \mathrm{dpa} / \mathrm{s}\end{array}$ & $\uparrow$ & $\uparrow$ & $\downarrow$ & $\uparrow^{1}$ & $\uparrow$ & $\downarrow$ & $\downarrow$ & $\uparrow$ & $\downarrow$ & $\begin{array}{l}\text { 1: The effect of } \mathrm{H} \text { refers to }(\mathrm{HI}+\mathrm{H}) \\
\text { vs. }(\mathrm{HI}) \text {. As temp. increases, the } \\
\text { swelling curves of different } \\
\text { irradiation beams cross }\end{array}$ & $\begin{array}{l}\text { Borodin et al. } \\
\text { (2013) }\end{array}$ \\
\hline & $\begin{array}{l}40 \mathrm{keV} \mathrm{He} \\
20 \mathrm{keV} \mathrm{H}\end{array}$ & $\begin{array}{l}20 \mathrm{appm} \mathrm{He} / \mathrm{dpa} \\
40 \mathrm{dppm} \mathrm{H/dpa}\end{array}$ & & & & $\uparrow$ & $\downarrow$ & $\uparrow$ & & & & & \\
\hline \multirow[t]{2}{*}{$\begin{array}{l}\text { Eurofer-97 } \\
\text { Eurofer-ODS }\end{array}$} & $3 \mathrm{MeV} \mathrm{Fe}$ & $\begin{array}{l}673 \mathrm{~K}, 26 \mathrm{dpa}, 1.3 \times 10^{-3} \\
\mathrm{dpa} / \mathrm{s}\end{array}$ & $\uparrow$ & $\uparrow$ & & $\uparrow$ & $\uparrow$ & $\uparrow$ & $\uparrow$ & $\uparrow$ & & & $\begin{array}{l}\text { Brimbal et al. } \\
\text { (2015) }\end{array}$ \\
\hline & $\begin{array}{l}1.2 \mathrm{MeV} \mathrm{He} \\
600 \mathrm{keV} \mathrm{H}\end{array}$ & $\begin{array}{l}17 \text { appm He/dpa, } \\
74 \text { dppm H/dpa }\end{array}$ & & & & & & & & & & & \\
\hline \multirow[t]{2}{*}{ EP 450 F82H } & $1.8 \mathrm{MeV} \mathrm{Cr}$ & $\begin{array}{l}753 \mathrm{~K}, 50 / 200 \mathrm{dpa}, 1 \times \\
10^{-2} \mathrm{dpa} / \mathrm{s},\end{array}$ & $\uparrow^{1}$ & $\uparrow$ & $\uparrow$ & $\uparrow^{3}$ & $\uparrow$ & $\downarrow$ & $\uparrow^{4}$ & $\uparrow$ & $\downarrow$ & $\begin{array}{l}\text { 1, 4: The comparison at } 50 \mathrm{dpa} \text {; } \\
\text { 2,5: The comparison at } 200 \mathrm{dpa} ; 3 \text { : } \\
\text { The effect of } \mathrm{H} \text { refers to }(\mathrm{HI}+\mathrm{H}) \\
\text { vs. }(\mathrm{HI})\end{array}$ & $\begin{array}{l}\text { Kupriiyanova et al. } \\
\text { (2016) }\end{array}$ \\
\hline & $\begin{array}{l}40 \mathrm{keV} \mathrm{He} \\
20 \mathrm{keV} \mathrm{H}\end{array}$ & $\begin{array}{l}\text { 0-160 appm He/dpa, } \\
\text { 0-200 dppm H/dpa }\end{array}$ & $\downarrow^{2}$ & $\uparrow$ & $\downarrow$ & & & & $\downarrow^{5}$ & $\uparrow$ & $\downarrow$ & & \\
\hline \multirow[t]{2}{*}{ Pure Fe } & $10 \mathrm{MeV} \mathrm{Fe}$ & $\begin{array}{l}623-823 \mathrm{~K}, 40 \mathrm{dpa}, 1.7 \times \\
10^{-3} \mathrm{dpa} / \mathrm{s}\end{array}$ & & $\uparrow$ & $\downarrow$ & & & & & & & $\begin{array}{l}\text { As temp. increases, swelling } \\
\text { increase, bubble-void transition } \\
\text { occurs }\end{array}$ & Roldán et al. (2016) \\
\hline & $\begin{array}{l}1.3 \mathrm{MeV} \mathrm{He} \\
600 \mathrm{keV} \mathrm{H}\end{array}$ & $\begin{array}{l}14 \text { appm He/dpa, } \\
50 \text { dppm H/dpa }\end{array}$ & & & & & & & & & & Bimodal cavities exist & \\
\hline \multirow[t]{2}{*}{ SCRAM $^{1}$} & $\begin{array}{l}\text { Sequential } \\
18 \mathrm{keV} \mathrm{He}\end{array}$ & $\begin{array}{l}723 \mathrm{~K} \\
1 \times 1,020 \mathrm{He} / \mathrm{m}^{2}\end{array}$ & & & & $\uparrow^{2}$ & $\uparrow$ & $\uparrow$ & & & & $\begin{array}{l}\text { 1: In-situ irradiation } \\
\text { 2: The effect of } \mathrm{H} \\
\text { obtained from the } \\
\text { sequential }(\mathrm{He}+\mathrm{H}) \text { irradiation }\end{array}$ & Chen et al. (2017) \\
\hline & $10 \mathrm{keV} \mathrm{H}$ & $0.1 / 1 / 4.2 \times 1,020 \mathrm{He} / \mathrm{m}^{2}$ & & & & & & & & & & & \\
\hline \multirow[t]{4}{*}{ Fe-10Cr Alloy ${ }^{1}$} & $\begin{array}{l}\text { Pre- } \\
\text { implantation }\end{array}$ & & & & & & & & & & & $\begin{array}{l}\text { 1: Pre-implantation } \mathrm{He} / \mathrm{H} \text {, then in- } \\
\text { situ electron irradiation }\end{array}$ & Liu et al. (2019) \\
\hline & $100 \mathrm{keV} \mathrm{He}$ & $1 \mathrm{dpa}, 2 \times 10^{-3} \mathrm{dpa} / \mathrm{s}$ & & & & & & & & & & & \\
\hline & $100 \mathrm{keV} \mathrm{H}$ & 6,500 appm He & & & & & & & & & & & \\
\hline & $\begin{array}{l}\text { Sequent } \\
1.25 \mathrm{MeV} \\
\text { Electron }\end{array}$ & 12,100 appm H & & & & & & & & & & & \\
\hline \multirow[t]{2}{*}{ Pure Cr } & $\begin{array}{l}5 \mathrm{MeV} \mathrm{Fe} \\
2.92 \mathrm{MeV} \mathrm{He}\end{array}$ & $\begin{array}{l}748 \mathrm{~K}, 53 \mathrm{dpa}, 4.38 \times \\
10^{-3} \mathrm{dpa} / \mathrm{s}\end{array}$ & $\downarrow$ & $\uparrow$ & $\downarrow$ & $\uparrow^{1}$ & $\downarrow$ & $\uparrow$ & $\downarrow$ & $\uparrow$ & $\downarrow$ & $\begin{array}{l}\text { 1: The effect of } \mathrm{H} \text { refers to }(H \mathrm{H}+\mathrm{H}) \\
\text { vs. }(H I)\end{array}$ & Jiang et al. (2020) \\
\hline & $270 \mathrm{keV} \mathrm{H}$ & $\begin{array}{l}12 \text { appm He/dpa, } \\
10 \text { dppm H/dpa }\end{array}$ & & & & $\uparrow$ & $\uparrow$ & $\uparrow$ & & & & & \\
\hline
\end{tabular}




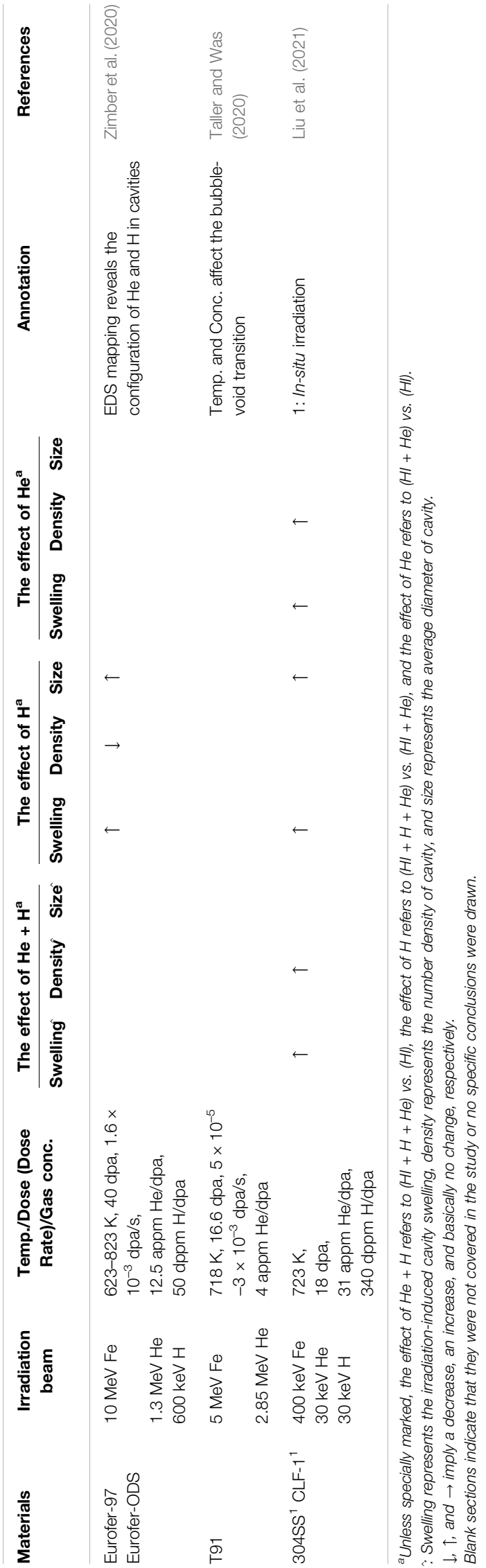

synergistic effects reduced the size. For instance, Roldán et al. (2016) noticed that cavities had the largest size when there was basically no gas but all displacement damage. However, at the depth of maximum concentration of $\mathrm{He}$ and $\mathrm{H}$, cavities had the highest density. This may be attributed to the synergistic effects on nucleation. Nevertheless, some results suggested that the synergistic effects would increase the average size of cavities, as shown in Table 1. For example, Zimber et al. (2020) found that the largest cavities always formed at the depth corresponding to the maximum displacement damage and concentration of $\mathrm{He}$ and $H$. This indicates that the synergistic effects may also prompt cavity growth. The different trends of synergistic effects on cavity size as well as swelling could be attributed to the different cumulative dose, material systems, irradiation temperatures, and implantation gas concentration (appm/dpa) in various experiments.

\section{THE ROLE OF HE AND H IN SYNERGISTIC EFFECTS}

As mentioned above, helium can stabilize vacancies clusters and promote cavity nucleation, and this process is affected by temperature (Monterrosa et al., 2018; Ni et al., 2020). This is confirmed by experimental results. In the column of "the effect of $\mathrm{He}$ " in Table 1, the presence of He in dual-beam irradiation increases the density and decreases the size of cavities in almost all cases. Besides, in some studies (Brimbal et al., 2015; Liu et al., 2021), researchers observed no cavities in materials under single $\mathrm{HI}$ irradiation, while cavities emerged under dual beam $(\mathrm{HI}+\mathrm{He})$ irradiation. This indicates the role of $\mathrm{He}$ in prompting cavity nucleation.

Unlike helium, there has been no consistent conclusion on the role of hydrogen, which may be the main source of the discrepancy in the $\mathrm{He}-\mathrm{H}$ synergistic effects. As shown in Table 1, the results suggest that $\mathrm{H}$ might have no obvious effects on the cavity, or prompt nucleation or/and growth process. The different effects might be influenced by irradiation dose, temperature, material systems, and gasdose ratio. Kupriiyanova et al. (2016) work supported the idea that $\mathrm{H}$ would prompt cavity nucleation. The researchers found that the presence of $\mathrm{H}$ in dual-ion beam $(\mathrm{HI}+\mathrm{H})$ irradiation resulted in an evident reduction of cavity average size, compared to that after single HI irradiation. Meanwhile, the density was greatly increased by about 100 times. As the implantation concentration of $\mathrm{H}$ increased, the cavity size slightly decreased and the density increased continually. Kano et al. (1993) suggested that a critical concentration of $\mathrm{H}$ was needed to prompt cavity nucleation. They found that there was no visible cavity under $(\mathrm{HI}+\mathrm{H})$ dual beam irradiation at first, but cavities emerged when the implantation concentration (appm/dpa) of $\mathrm{H}$ was high enough.

Sekimura et al. (2000) and Tanaka et al. (2004) both suggested that $\mathrm{H}$ may have little effects on cavity evolution when interacting with vacancies alone, because the cavity size, density, and swelling were all nearly unchanged under (HI + 
$\mathrm{H})$ dual beam irradiation compared to single HI irradiation. However, compared to $(\mathrm{HI}+\mathrm{He})$ dual beam, the introduction of $\mathrm{H}$ in triple beam significantly increased the size of the cavity and reduced the density, and the swelling was also enhanced. This indicated that $\mathrm{H}$ could prompt the growth of cavity effectively. And the different role of $\mathrm{H}$ in these two situations implied that $\mathrm{H}$ might exhibit a significant effect mainly in the synergistic effects of $\mathrm{He}, \mathrm{H}$, and vacancies.

However, Jiang et al. (2020) reported a distinct effect of $\mathrm{H}$ on prompting cavity growth under $(\mathrm{HI}+\mathrm{H})$ dual beam irradiation. The presence of $\mathrm{H}$ in dual beam increased the size of cavities and reduced the density significantly, resulting in the maximum swelling. Additionally, the size and density of cavities under $(\mathrm{HI}+\mathrm{H}+\mathrm{He})$ triple beam irradiation increased compared to $(\mathrm{HI}+\mathrm{He})$ dual beam, indicating that $\mathrm{H}$ could prompt both the nucleation and growth of cavities in synergistic effects.

The difference in the effects of $\mathrm{H}$ between the comparison of $(\mathrm{HI}+\mathrm{H})$ vs. $\mathrm{HI}$ and $(\mathrm{HI}+\mathrm{H}+\mathrm{He})$ vs. $(\mathrm{HI}+\mathrm{He})$ could be explained by the instability of $\mathrm{H}-\mathrm{V}$ clusters, from which $\mathrm{H}$ could dissociate and escape under some conditions. In contrast, the He$\mathrm{H}-\mathrm{V}$ clusters formed in $\mathrm{He}-\mathrm{H}$ synergistic effects are more stable. Chen et al. (2017) found that, compared to sequential $\mathrm{He}-\mathrm{H}$ irradiation, the size of cavities and swelling decreased obviously under sequential $\mathrm{H}-\mathrm{He}$ irradiation. They proposed that this was attributed to the decomposition of $\mathrm{H}-\mathrm{V}$ clusters at high temperatures which formed during $\mathrm{H}$ implantation first. Nevertheless, under sequential $\mathrm{He}-\mathrm{H}$ irradiation, the postimplanted $\mathrm{H}$ could be trapped by relatively stable $\mathrm{He}-\mathrm{V}$ clusters, resulting in the increase of $\mathrm{H}$ concentration in the clusters and swelling. In materials under triple beam simultaneously irradiation, the stable $\mathrm{He}-\mathrm{V}$ clusters would also capture $\mathrm{H}$ to form $\mathrm{He}-\mathrm{H}-\mathrm{V}$ clusters and dominate the evolution of cavities (Jin et al., 2019).

\section{THE ROLE OF GAS-DOSE RATIO IN SYNERGISTIC EFFECTS}

In synergistic effects, gas-dose ratio also has a significant influence on the characteristics and evolution of cavities and further affects the swelling values of materials. As mentioned above, the synergistic effects would usually prompt the nucleation and dispersion of cavities. As gas concentration increases, the cavity size decreases, and thus the swelling might be suppressed. The critical concentration, if exists, depends on the specific materials and irradiation conditions. Sekimura et al. (2000) found that the vanadium alloy reached the maximum swelling when the gas-dose ratio of $\mathrm{He}$ and $\mathrm{H}$ was both $10 \mathrm{appm} / \mathrm{dpa}$. As shown in Figure 4, the swelling decreased as the gas-dose ratio slightly increased or decreased. And irradiation with higher gas concentration could induce a higher cavity density but a smaller size. This trend was also found in $\mathrm{F} 82 \mathrm{H}$ steel after triple-ion beam irradiation with the gas-dose ratio ranging from $18 \mathrm{appm}$ $\mathrm{He} / \mathrm{dpa}$ and $70 \mathrm{appm} \mathrm{H/dpa} \mathrm{to} 180 \mathrm{appm} \mathrm{He/dpa} \mathrm{and}$ 1,800 appm H/dpa (Wakai et al., 2003).

\section{THE ROLE OF TEMPERATURE IN SYNERGISTIC EFFECTS}

It is expected that temperature plays an important role in the He$\mathrm{H}$ synergistic effects because the stability and motility of clusters as well as the formation and growth of cavities are strongly temperature dependent. Based on the dependence of point defects motion on temperature, there would be a peak swelling temperature under both single $\mathrm{HI}$ and multi-ion beam irradiation (Lin et al., 2021). In the 1980s, Horton et al. (1981) reported that the swelling of Fe-10Cr alloy reached its maximum swelling under triple beam irradiation at $850 \mathrm{~K}$, which was $150 \mathrm{~K}$ higher than that under fast neutron irradiation. When the temperature was below $800 \mathrm{~K}$, no cavity was found. As temperature increased, the average size of cavities increased first and then decreased, the trend density was opposite. These results indicate that below the peak swelling temperature, the increase of temperature would prompt the growth of cavities and subsequently dominate the swelling.

As shown in Figure 5, Borodin et al. (2013) systematically investigated the behaviors of cavities in AUSS after irradiation between 723 and $923 \mathrm{~K}$. The results showed a slight shift in the peak swelling temperature under single and multi-beam irradiation, meanwhile the swelling was enhanced by $\mathrm{He}-\mathrm{H}$ synergistic effects over the entire temperature window. And it was noteworthy that below the peak swelling temperature, the swelling under triple beam irradiation was always higher than those under dual beam irradiation. However, the $(\mathrm{HI}+\mathrm{H})$ dual beam caused the maximum swelling at the peak swelling temperature, which was attributed to the second-largest cavity size. This suggests that the diffusion and trapping processes of $\mathrm{He}$ and $\mathrm{H}$ in synergistic effects could be directly affected by temperature, leading to significant influence on cavity properties and swelling. Overall, as the temperature increased, the density of cavities decreased while the size increased under all irradiation conditions.

The influence of temperatures was also observed in Wakai et al. (2003). As the temperature increased from 743 to $873 \mathrm{~K}$, the swelling in $\mathrm{F} 82 \mathrm{H}$ steel under triple beam irradiation with 18 appm He/dpa and 70 appm H/dpa decreased sharply from $3.2 \%$ to $0.09 \%$, which was mainly due to the decrease of cavity density. Meanwhile, there was only a slight decrease in swelling induced by dual beam irradiation. In particular, they found that the results were quite different under triple beam irradiation with spallation-relevant gas production rate, i.e., $180 \mathrm{appm} \mathrm{He/dpa} \mathrm{and} \mathrm{1,800} \mathrm{appm} \mathrm{H/dpa.} \mathrm{It} \mathrm{was} \mathrm{shown}$ that the swelling first decreased from $1.2 \%$ to $0.29 \%$ and then increased to $1.0 \%$ with increasing temperature, while the cavity size decreased and the density increased continually.

\section{BIMODAL SIZE DISTRIBUTION OF CAVITY IN SYNERGISTIC EFFECTS}

In addition, temperature will affect the proportion of vacancies to $\mathrm{H} / \mathrm{He}$ atoms in the cavity by affecting the motility and binding of vacancy and gas atoms. As a result, cavities might transform between void-like and bubble-like as the 

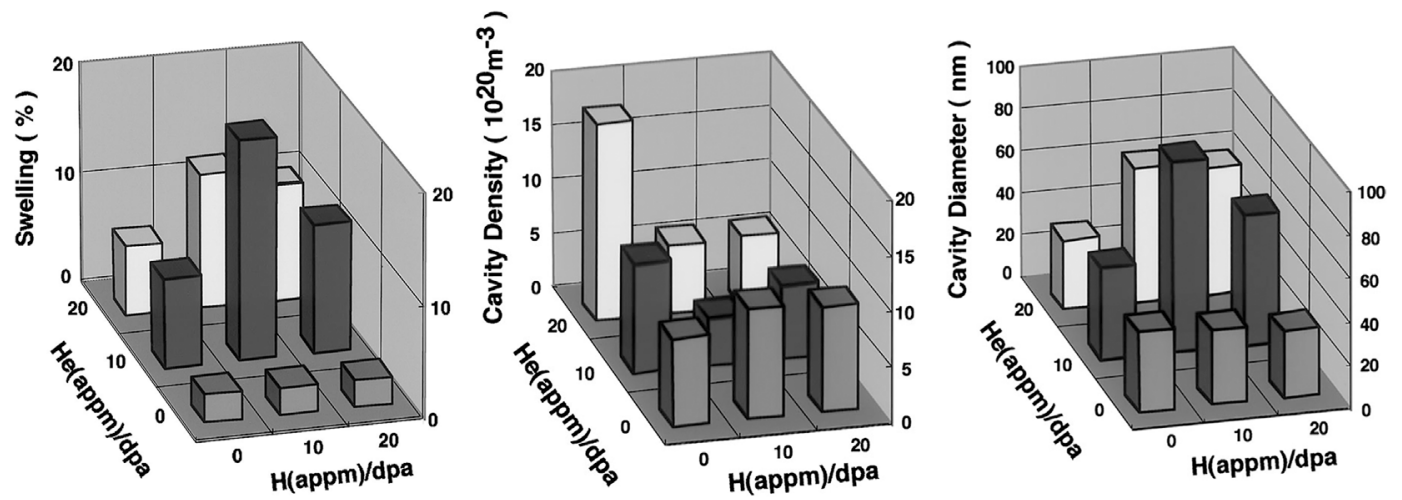

FIGURE 4 | The synergistic effects on vanadium alloy irradiated with different gas-dose ratio of $\mathrm{He}$ and $\mathrm{H}$. It reached the maximum swelling at 10 appm $\mathrm{He} / \mathrm{dpa}$ and $10 \mathrm{appmH} / \mathrm{dpa}$ (Sekimura et al., 2000).
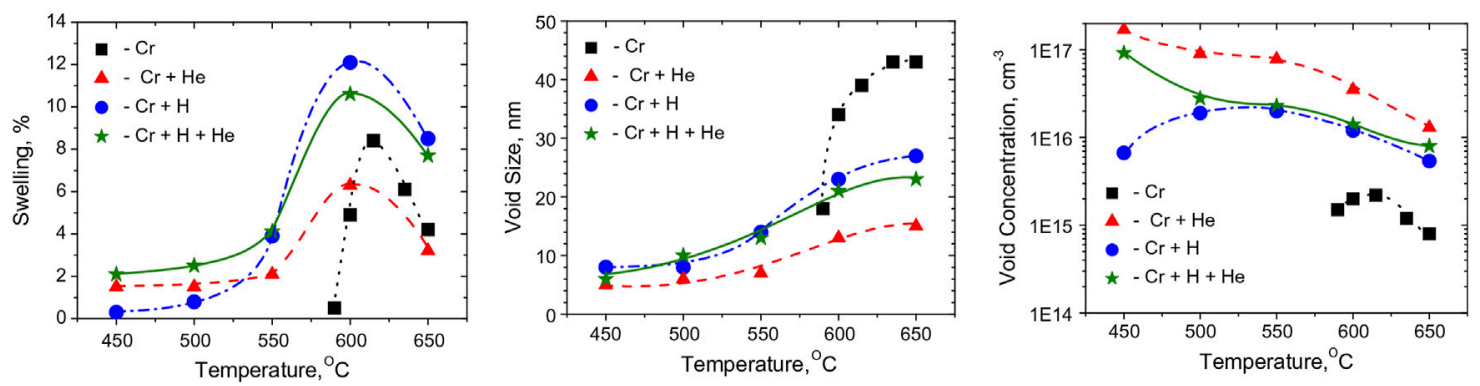

FIGURE 5 | The dependence of synergistic effects on temperature in AUSS. The peak swelling temperature has a slight shift under single and multi-beam irradiation. And at the peak swelling temperature, the $(\mathrm{HI}+\mathrm{H})$ dual beam irradiation causes the maximum swelling (Borodin et al., 2013).

temperature changes. And these two types of cavities, which differ in size and shape, are often observed to coexist in materials after irradiated in the study of $\mathrm{He}-\mathrm{H}$ synergistic effects (Taller et al., 2019; Liu et al., 2021).

Roldán et al. (2016) reported that, in irons irradiated by triple-ion beam, as the temperature increased from 623 to $723 \mathrm{~K}$, there appeared both large polygonal faceted and small circular shapes cavities where previously only smaller circular cavities existed. This indicated the transition of bubble-like cavities to void-like cavities. The coexistence of large and small cavities is known as bimodal size distribution and was predicted by early modeling work (Odette, 1979; Hishinuma and Mansur, 1983). The bimodal distribution may result from the transition regimes of cavity evolution (Getto et al., 2017), and sometimes would be eliminated at high temperatures. The elimination may be due to the completion of transition (Roldán et al., 2016) or the disappearance of bias-driven sources, such as dislocations (Farrell and Lee, 1987). In addition, there might be a critical cavity size for the transition in bimodal distribution, which mainly depends on the temperature and gas-dose ratio (Taller and Was, 2020).

Recently, the distribution of gas atoms in cavities was investigated. In 2020, Zimber et al. (2020) confirmed the existence of $\mathrm{He}$ and $\mathrm{H}$ inside a large cavity by EELS
(Electron Energy Loss Spectroscopy). The results suggested that gas was present throughout the whole cavity, where helium formed a core-like structure in the center and $\mathrm{H}$ occupied also further peripheral area. The results were consistent with modeling works (Hayward and Deo, 2012), which indicated that the stable configuration of clusters may have a core of helium and be surrounded by a shell of hydrogen atoms attached to the free surface, as shown in Figure 6.

\section{THE ROLE OF DAMAGE RATE IN SYNERGISTIC EFFECTS}

As mentioned earlier in Horton et al. (1981), the peak swelling temperature usually has a shift of up to hundreds Kelvin between ion and neutron irradiation conditions due to the great difference in damage rates (Saidi et al., 2021). Likewise, the damage rate in multi-ion beam irradiation, including dose rate and gas implantation rate (appm/s), are 3 to 4 orders of magnitude higher than that in fusion neutron irradiation conditions. The different damage rates could significantly affect the formation and evolution of cavities, and this huge difference has led to questions about the results obtained from multi-ion beam irradiation. However, there are barely experimental studies on 

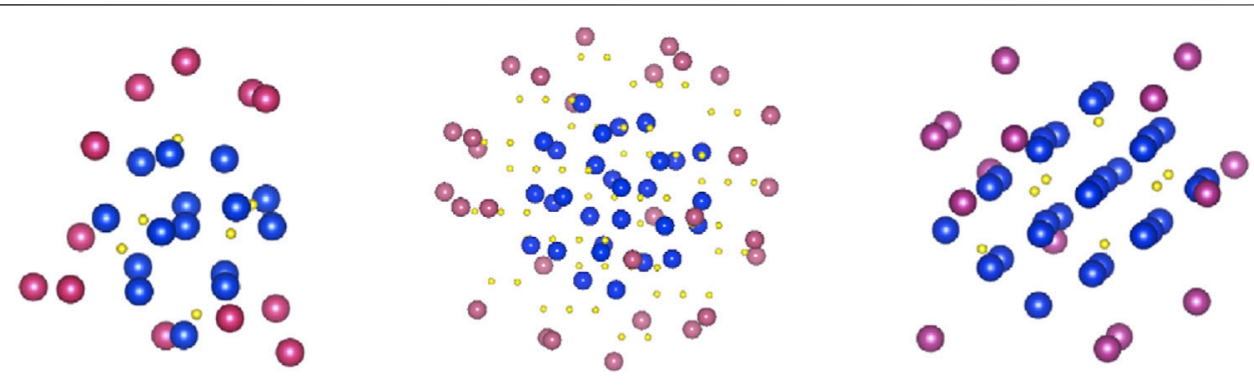

FIGURE 6 | The stable configurations of He-H-V clusters. The small yellow circles represent vacancies, pink ones represent hydrogen atoms, and blue ones represent helium atoms (Hayward and Deo, 2012).

the influence of damage rate on He-H synergistic effects so far, except for one or two explorations under $(\mathrm{HI}+\mathrm{He})$ dual-ion beam (Taller and Was, 2020).

In summary, the He-H synergistic effects usually prompt the nucleation of cavity when $\mathrm{He}$ and $\mathrm{H}$ are both present, while the swelling might be enhanced or suppressed. He can effectively stabilize vacancy clusters and prompt the nucleation and dispersion of cavities, resulting in the increase of cavities number density and decrease of size. However, the specific effects of $\mathrm{H}$ are still not clear. It seems that $\mathrm{H}$ could be trapped by $\mathrm{He}-\mathrm{V}$ clusters and strengthen the binding of $\mathrm{He}$ and $\mathrm{V}$, reducing the surface energy to prompt the growth of cavity.

\section{CONCLUSION AND PERSPECTIVES}

Up to now, the majority of experimental studies on $\mathrm{He}-\mathrm{H}$ synergistic effects induced by fusion neutron irradiation were based on multi-ion beam irradiation. However, these results are not always consistent. Due to the lack of comprehensive understanding of the mechanism of synergistic effects, it is challenging to obtain a convincing conclusion about the possible synergistic damage to blanket structural materials in fusion reactors.

The swelling data may be sufficient to describe the cavity damage effects under single heavy ion irradiation. However, due to the complicated effects of $\mathrm{He}$ and $\mathrm{H}$ on cavity nucleation and growth processes under multi-ion beam irradiation, it is necessary to focus on the specific characteristics of cavity, such as size and number density. There exist many factors that can significantly influence the synergistic effects, including irradiation dose, temperature, dose rate, implantation rate (appm/s) and gasdose ratio (appm/dpa) of $\mathrm{He}$ and $\mathrm{H}$, and materials properties. This suggests that systematic-controlled and carefully designed experiments are needed to study the specific roles of various

\section{REFERENCES}

Abramov, E., and Eliezer, D. (1988). Trapping of Hydrogen in Helium-Implanted Metals. J. Mater. Sci. Lett. 7, 108-110. doi:10.1007/ bf01730586 factors in synergistic damage. Meanwhile, computational simulations are powerful tools for exploring the original interaction process and mechanism. Advanced and efficient multi-scale computational methods should be developed and combined with experimental methods to explore the mechanisms of synergistic effects.

Multi-ion beam irradiation cannot emulate fusion neutron irradiation yet. One of the greatest obstacles is the extremely high damage rate in multi-beam irradiation, where the dose rate is determined by both the beam currents and the energy deposited density. During the He$\mathrm{H}$ synergistic effect, the effects of dose rate and gas implantation rate $(\mathrm{appm} / \mathrm{s})$ on swelling and yield strength change should be considered in depth. And in actual irradiation experiments, the damage rate should be reduced as much as reasonably possible to better emulate the fusion neutron irradiation conditions.

\section{AUTHOR CONTRIBUTIONS}

YW and CW conceived the research and designed the structure of this review. JH, YW, and $\mathrm{CW}$ wrote and edited the manuscript. HL, ZG, YS, QL, WG, FL, SX, LC, and JX made contributions to reviewing and editing. All authors have read and agreed to the published version of the manuscript.

\section{FUNDING}

This work was supported by the National Natural Science Foundation of China (Grant No. 12192280), and State Key Laboratory of Nuclear Physics and Technology, Peking University (Grant No. NPT2020KFY09) and National Magnetic Confinement Fusion Energy Research Project 2021YFE031100.

Bhattacharya, A., and Zinkle, S. J. (2020). "Cavity Swelling in Irradiated Materials," in Comprehensive Nuclear Materials. Editors R. Konings and R. Stoller. 2nd edition (Amsterdam: Elsevier), Vol. 1, 406-455. doi:10.1016/b978-0-12-803581-8.11599-1 Binyukova, S. Y., Chernov, I. I., Kalin, B. A., and Swe, T. (2007). Effectiveness of Helium Bubbles as Traps for Hydrogen. J. Nucl. Mater. 367-370, 500-504. doi:10.1016/j.jnucmat.2007.03.110 
Borodin, O. V., Bryk, V. V., Kalchenko, A. S., Melnichenko, V. V., Voyevodin, V. N., and Garner, F. A. (2013). Synergistic Effects of Helium and Hydrogen on Self-Ion-Induced Swelling of Austenitic 18Cr10NiTi Stainless Steel. J. Nucl. Mater. 442, S817-S820. doi:10.1016/j.jnucmat.2013.05.022

Brimbal, D., Beck, L., Troeber, O., Gaganidze, E., Trocellier, P., Aktaa, J., et al. (2015). Microstructural Characterization of Eurofer-97 and Eurofer-ODS Steels before and after Multi-Beam Ion Irradiations at JANNUS Saclay Facility. J. Nucl. Mater. 465, 236-244. doi:10.1016/j.jnucmat.2015.05.045

Chen, J., Guo, L., Luo, F., Li, T., Ren, Y., and Suo, J. (2017). Synergistic Effects in Reduced-Activation Martensitic Steel under Single and Sequential Helium/Hydrogen Ion Irradiation. Fusion Sci. Techn. 66 (2), 301-307. doi:10.13182/fst13-714

Dai, Y., Odette, G. R., and Yamamoto, T. (2020). "The Effects of Helium in Irradiated Structural Alloys," in Comprehensive Nuclear Materials. Editors R. Konings and R. Stoller. 2nd edition (Amsterdam: Elsevier), Vol. 1, 186-234. doi:10.1016/b978-0-12-803581-8.12046-6

Donné, A. J. (2019). Roadmap towards Fusion Electricity (Editorial). J. Fusion Energ. 38 (5-6), 503-505. doi:10.1007/s10894-019-00223-7

Farrell, K., and Lee, E. (1985). Ion Bombardment Damage in a Modified Fe9Cr-1Mo Steel. Philadelphia: American Society for Testing and Materials, 383-393.

Farrell, K., and Lee, E. (1987). Ion Damage in a Fe-10Cr-6Mo-0.5Nb Ferritic Steel. Philadelphia: American Society for Testing and Materials, 498-507.

Farrell, K., Lewis, M. B., and Packan, N. H. (1978). Simultaneous Bombardment with Helium, Hydrogen, and Heavy Ions to Simulate Microstructural Damage from Fission or Fusion Neutrons. Scr. Metal. 12 (12), 1121-1124. doi:10.1016/0036-9748(78)90087-X

Getto, E., Vancoevering, G., and Was, G. S. (2017). The Co-evolution of Microstructure Features in Self-Ion Irradiated HT9 at Very High Damage Levels. J. Nucl. Mater. 484, 193-208. doi:10.1016/j.jnucmat.2016.12.006

Hamada, S., Zhang, Y. C., Miwa, Y., and Yamaki, D. (1997). Effect of Triple Beam Irradiation on Microstructural Evolution in Austenitic Stainless Steel. Radiat. Phys. Chem. 50 (6), 555-559. doi:10.1016/S0969-806x(97)00102-3

Hashimoto, N., Klueh, R. L., and Shiba, K. (2002). Pros and Cons of Nickel- and boron-doping to Study Helium Effects in Ferritic/martensitic Steels. J. Nucl. Mater. 307-311, 222-228. doi:10.1016/s0022-3115(02)01183-2

Hayward, E., and Deo, C. (2012). Synergistic Effects in Hydrogen-Helium Bubbles. J. Phys. Condens. Matter 24 (26), 265402. doi:10.1088/0953-8984/24/26/265402

Heinisch, H. L. (1988). Effects of the Neutron Spectrum on Mechanical Property Changes in Low Dose Irradiations. J. Nucl. Mater. 155-157, 121-129. doi:10. 1016/0022-3115(88)90234-6

Henriksson, K. O. E., Nordlund, K., Krasheninnikov, A., and Keinonen, J. (2005). Difference in Formation of Hydrogen and Helium Clusters in Tungsten. Appl. Phys. Lett. 87 (16), 163113. doi:10.1063/1.2103390

Hishinuma, A., and Mansur, L. K. (1983). Critical Radius for Bias-Driven Swelling - a Further Analysis and its Application to Bimodal Cavity Size Distributions. J. Nucl. Mater. 118 (1), 91-99. doi:10.1016/0022-3115(83)90184-8

Horton, L. L., Bentley, J., and Jesser, W. A. (1981). The Microstructure of "TripleBeam" Ion Irradiated Fe and Fe-Cr Alloys. J. Nucl. Mater. 104, 1085-1089. doi:10.1016/0022-3115(82)90745-0

Jia, X., and Dai, Y. (2006). Microstructure of the F82H Martensitic Steel Irradiated in STIP-II up to 20dpa. J. Nucl. Mater. 356 (1-3), 105-111. doi:10.1016/j. jnucmat.2006.05.006

Jiang, L., Peng, Q., Xiu, P., Yan, Y., Jiao, Z., Lu, C., et al. (2020). Elucidating He-H Assisted Cavity Evolution in Alpha Cr under Multiple Ion Beam Irradiation. Scr. Mater. 187, 291-295. doi:10.1016/j.scriptamat.2020.06.031

Jin, P., Shen, T., Cui, M., Zhu, Y., Li, B., Zhang, T., et al. (2019). Study on Vacancy-type Defects in SIMP Steel Induced by Separate and Sequential H and He Ion Implantation. J. Nucl. Mater. 520, 131-139. doi:10.1016/j. jnucmat.2019.04.012

Jung, P., Liu, C., and Chen, J. (2001). Retention of Implanted Hydrogen and Helium in Martensitic Stainless Steels and Their Effects on Mechanical Properties. J. Nucl. Mater. 296 (1-3), 165-173. doi:10.1016/s0022-3115(01) 00545-1

Kano, F., Arai, Y., Fukuya, K., Sekimura, N., and Ishino, S. (1993). The Effect of Hydrogen on Microstructural Changes Using Dual Ion Irradiation. J. Nucl. Mater. 203 (2), 151-157. doi:10.1016/0022-3115(93)90051-Y
Kiritani, M., Yoshida, N., and Ishino, S. (1984). The Japanese Experimental Program on RTNS-II of DT-Neutron Irradiation of Materials. J. Nucl. Mater. 122 (1-3), 602-607. doi:10.1016/0022-3115(84)90666-4

Kiritani, M., Yoshiie, T., Kojima, S., Satoh, Y., and Hamada, K. (1990). Fissionfusion Correlation by Fission Reactor Irradiation with Improved Control. J. Nucl. Mater. 174 (2-3), 327-351. doi:10.1016/0022-3115(90)90245-i

Knaster, J., Moeslang, A., and Muroga, T. (2016). Materials Research for Fusion. Nat. Phys 12 (5), 424-434. doi:10.1038/Nphys3735

Kupriiyanova, Y. E., Bryk, V. V., Borodin, O. V., Kalchenko, A. S., Voyevodin, V. N., Tolstolutskaya, G. D., et al. (2016). Use of Double and Triple-Ion Irradiation to Study the Influence of High Levels of Helium and Hydrogen on Void Swelling of 8-12\% Cr Ferritic-Martensitic Steels. J. Nucl. Mater. 468, 264-273. doi:10.1016/j.jnucmat.2015.07.012

Lin, Y.-R., Bhattacharya, A., Chen, D., Kai, J.-J., Henry, J., and Zinkle, S. J. (2021). Temperature-dependent Cavity Swelling in Dual-Ion Irradiated Fe and $\mathrm{Fe}-\mathrm{Cr}$ Ferritic Alloys. Acta Mater. 207, 116660. doi:10.1016/j.actamat.2021.116660

Liu, P. P., Zhan, Q., Han, W. T., Yi, X. O., Ohnuki, S., and Wan, F. R. (2019). Effect of Helium and Hydrogen Synergy on Vacancy Migration Energy in Fe-10Cr Model alloy. J. Alloys Compd. 788, 446-452. doi:10.1016/j.jallcom.2019.02.227

Liu, H., Huang, J., Cao, L., Su, Y., Gao, Z., Ma, P., et al. (2021). Helium-hydrogen Synergistic Effects on Swelling in In-Situ Multiple-Ion Beams Irradiated Steels*. Chin. Phys. B 30 (8), 086106. doi:10.1088/1674-1056/abfcca

Marian, J., Hoang, T., Fluss, M., and Hsiung, L. L. (2015). A Review of HeliumHydrogen Synergistic Effects in Radiation Damage Observed in Fusion Energy Steels and an Interaction Model to Guide Future Understanding. J. Nucl. Mater. 462, 409-421. doi:10.1016/j.jnucmat.2014.12.046

Matsui, H., Abe, K., Hirano, S., Yoshinari, O., and Koiwa, M. (1985). Irradiation Hardening of Iron and Vanadium by Fission and Fusion Neutrons. J. Nucl. Mater. 133-134, 615-618. doi:10.1016/0022-3115(85)90221-1

Matsui, H., Takehana, S., and Guinan, M. W. (1988). Resistivity Recovery in High Purity Iron after Fission- and Fusion- Neutron Irradiation. J. Nucl. Mater. 155157, 1284-1289. doi:10.1016/0022-3115(88)90512-0

Molvik, A., Ivanov, A., Kulcinski, G. L., Ryutov, D., Santarius, J., Simonen, T., et al. (2010). A Gas Dynamic Trap Neutron Source for Fusion Material and Subcomponent Testing. Fusion Sci. Techn. 57 (4), 369-394. doi:10.13182/ fst10-a9499

Monterrosa, A. M., Jiao, Z., and Was, G. S. (2018). The Influence of Helium on Cavity Evolution in Ion-Irradiated T91. J. Nucl. Mater. 509, 707-721. doi:10. 1016/j.jnucmat.2018.06.033

Muroga, T., Watanabe, H., Araki, K., and Yoshida, N. (1988). Fission-fusion Correlation of Void Swelling in Pure Nickel. J. Nucl. Mater. 155-157, 1290-1295. doi:10.1016/0022-3115(88)90513-2

Muroga, T., Heinisch, H. L., Sommer, W. F., and Ferguson, P. D. (1992). A Comparison of Microstructures in Copper Irradiated with Fission, Fusion and Spallation Neutrons. J. Nucl. Mater. 191-194, 1150-1154. doi:10.1016/00223115(92)90655-5

Muroga, T., Möslang, A., and Diegele, E. (2020). Users' Perspective on D-Li Neutron Sources (A-FNS and IFMIF-DONES) for DEMO and beyond. J. Nucl. Mater. 535, 152186. doi:10.1016/j.jnucmat.2020.152186

Ni, W., Zhang, Y., Cui, Y., Niu, C., Liu, L., Fan, H., et al. (2020). The Effect of Fusion-Relevant He Ion Flux on the Evolution of He Nano-Bubbles in W. Plasma Phys. Control Fusion 62 (6), 065002. doi:10.1088/1361-6587/ab8242

Odette, G. R. (1979). Modeling of Microstructural Evolution under Irradiation. J. Nucl. Mater. 85-86, 533-545. doi:10.1016/0022-3115(79)90542-7

Okada, A., Yasujima, T., Yoshiie, T., Ishida, I., and Kiritani, M. (1991). Mechanical Property Changes and Microstructures of Iron Irradiated with Fission and Fusion Neutrons. J. Nucl. Mater. 179-181, 1083-1087. doi:10.1016/00223115(91)90280-k

Oliver, B. M., Dai, Y., and Causey, R. A. (2006). Helium and Hydrogen Release Measurements on Various Alloys Irradiated in SINQ. J. Nucl. Mater. 356 (1-3), 148-156. doi:10.1016/j.jnucmat.2006.05.025

Roldán, M., Fernández, P., Vila, R., Gómez-Herrero, A., and Sánchez, F. J. (2016). The Effect of Triple Ion Beam Irradiation on Cavity Formation on Pure EFDA Iron. J. Nucl. Mater. 479, 100-111. doi:10.1016/j.jnucmat.2016.06.043

Saidi, P., Topping, M., Dai, C., Long, F., Béland, L. K., and Daymond, M. R. (2021). The Dependence of Damage Accumulation on Irradiation Dose Rate in Zirconium Alloys: Rate Theory, Atomistic Simulation and 
Experimental Validation. J. Nucl. Mater. 543, 152478. doi:10.1016/j. jnucmat.2020.152478

Sekimura, N., Iwai, T., Arai, Y., Yonamine, S., Naito, A., Miwa, Y., et al. (2000). Synergistic Effects of Hydrogen and Helium on Microstructural Evolution in Vanadium Alloys by Triple Ion Beam Irradiation. J. Nucl. Mater. 283287, 224-228. doi:10.1016/S0022-3115(00)00341-X

Shimomura, Y., Guinan, M. W., and Kiritani, M. (1985). Low Temperature D-T Neutron Irradiation and Cryotransfer Observation of cascade Defects of Metals. J. Nucl. Mater. 133-134, 415-419. doi:10.1016/0022-3115(85) 90179-5

Shimomura, Y., Guinan, M. W., Fukushima, H., Hahn, P. A., and Kiritani, M. (1988). 20 K Cryo-Transfer Tem Observation of Nascent Displacement cascade Damages in Low Temperature D-T Neutron-Irradiated Metals at RTNS-II. J. Nucl. Mater. 155-157, 1181-1187. doi:10.1016/0022-3115(88) 90492-8

Singh, B. N., and Zinkle, S. J. (1993). Defect Accumulation in Pure Fcc Metals in the Transient Regime: a Review. J. Nucl. Mater. 206 (2-3), 212-229. doi:10.1016/0022-3115(93)90125-i

Stork, D., Heidinger, R., Muroga, T., Zinkle, S. J., Moeslang, A., Porton, M., et al. (2017). Towards a Programme of Testing and Qualification for Structural and Plasma-Facing Materials in 'fusion Neutron' Environments. Nucl. Fusion 57 (9), 092013. doi:10.1088/1741-4326/aa60af

Taller, S., and Was, G. S. (2020). Understanding Bubble and Void Nucleation in Dual Ion Irradiated T91 Steel Using Single Parameter Experiments. Acta Mater. 198, 47-60. doi:10.1016/j.actamat.2020.07.060

Taller, S., Jiao, Z., Field, K., and Was, G. S. (2019). Emulation of Fast Reactor Irradiated T91 Using Dual Ion Beam Irradiation. J. Nucl. Mater. 527, 151831. doi:10.1016/j.jnucmat.2019.151831

Tanaka, T., Oka, K., Ohnuki, S., Yamashita, S., Suda, T., Watanabe, S., et al. (2004). Synergistic Effect of Helium and Hydrogen for Defect Evolution under Multi-Ion Irradiation of Fe-Cr Ferritic Alloys. J. Nucl. Mater. 329333, 294-298. doi:10.1016/j.jnucmat.2004.04.051

Tanigawa, H., Shiba, K., Möslang, A., Stoller, R. E., Lindau, R., Sokolov, M. A., et al. (2011). Status and Key Issues of Reduced Activation Ferritic/ martensitic Steels as the Structural Material for a DEMO Blanket. J. Nucl. Mater. 417 (1-3), 9-15. doi:10.1016/j.jnucmat.2011.05.023

Trinkaus, H., and Singh, B. N. (2003). Helium Accumulation in Metals during Irradiation - where Do We Stand? J. Nucl. Mater. 323 (2-3), 229-242. doi:10.1016/j.jnucmat.2003.09.001

Wakai, E., Sawai, T., Furuya, K., Naito, A., Aruga, T., Kikuchi, K., et al. (2002). Effect of Triple Ion Beams in Ferritic/martensitic Steel on Swelling Behavior. J. Nucl. Mater. 307-311 (3), 278-282. doi:10.1016/s00223115(02)01076-0

Wakai, E., Kikuchi, K., Yamamoto, S., Aruga, T., Ando, M., Tanigawa, H., et al. (2003). Swelling Behavior of F82H Steel Irradiated by Triple/dual Ion Beams. J. Nucl. Mater. 318, 267-273. doi:10.1016/s0022-3115(03)00122-3
Was, G. S., Jiao, Z., Getto, E., Sun, K., Monterrosa, A. M., Maloy, S. A., et al. (2014) Emulation of Reactor Irradiation Damage Using Ion Beams. Scr. Mater. 88, 33-36. doi:10.1016/j.scriptamat.2014.06.003

Was, G. S., Petti, D., Ukai, S., and Zinkle, S. (2019). Materials for Future Nuclear Energy Systems. J. Nucl. Mater. 527, 151837. doi:10.1016/j.jnucmat.2019. 151837

Was, G. S. (2015). Challenges to the Use of Ion Irradiation for Emulating Reactor Irradiation. J. Mater. Res. 30 (9), 1158-1182. doi:10.1557/jmr.2015.73

Zimber, N., Vladimirov, P., Klimenkov, M., Jäntsch, U., Vila, R., Chakin, V., et al. (2020). Microstructural Evolution of Three Potential Fusion Candidate Steels under Ion-Irradiation. J. Nucl. Mater. 535, 152160. doi:10.1016/j.jnucmat.2020. 152160

Zinkle, S. J., and Busby, J. T. (2009). Structural Materials for Fission \& Fusion Energy. Mater. Today 12 (11), 12-19. doi:10.1016/s1369-7021(09)70294-9

Zinkle, S. J., and Snead, L. L. (2014). Designing Radiation Resistance in Materials for Fusion Energy. Annu. Rev. Mater. Res. 44 (1), 241-267. doi:10.1146/ annurev-matsci-070813-113627

Zinkle, S. J., and Snead, L. L. (2018). Opportunities and Limitations for Ion Beams in Radiation Effects Studies: Bridging Critical Gaps between Charged Particle and Neutron Irradiations. Scr. Mater. 143, 154-160. doi:10.1016/j.scriptamat. 2017.06.041

Zinkle, S. J. (2020). "Radiation-Induced Effects on Microstructure," in Comprehensive Nuclear Materials. Editors R. Konings and R. Stoller. 2nd edition (Amsterdam: Elsevier), Vol. 1, 92-129. doi:10.1016/b978-0-12803581-8.12075-2

Conflict of Interest: Author HL is employed by State Power Investment Corporation Research Institute.

The remaining authors declare that the research was conducted in the absence of any commercial or financial relationships that could be construed as a potential conflict of interest.

Publisher's Note: All claims expressed in this article are solely those of the authors and do not necessarily represent those of their affiliated organizations, or those of the publisher, the editors and the reviewers. Any product that may be evaluated in this article, or claim that may be made by its manufacturer, is not guaranteed or endorsed by the publisher.

Copyright (c) 2022 Huang, Liu, Gao, Su, Liu, Ge, Luo, Xia, Cao, Xue, Wang and Wang. This is an open-access article distributed under the terms of the Creative Commons Attribution License (CC BY). The use, distribution or reproduction in other forums is permitted, provided the original author(s) and the copyright owner(s) are credited and that the original publication in this journal is cited, in accordance with accepted academic practice. No use, distribution or reproduction is permitted which does not comply with these terms. 